\title{
GESTÃO EDUCACIONAL
}




\title{
A GESTÃO DEMOCRÁTICA DO ENSINO PÚBLICO NA GANGORRA DOS ACONTECIMENTOS POLÍTICO- IDEOLÓGICOS NO RIO GRANDE DO SUL
}

\author{
Maria Elizabete Londero Mousquer
}

\begin{abstract}
Resumo
$\mathrm{O}$ artigo apresenta extrato de uma pesquisa que objetiva compreender as mudanças na gestão da educação na rede estadual de ensino do RS, no momento em que se encaminha uma reforma na educação pública, incluindo alterações no processo de gestão. Pretende-se identificar os significados desta proposta para a democracia no ensino público, partindo do questionamento que persiste a longo tempo sobre a função da gestão democrática. O trabalho ancora-se na abordagem qualitativa de pesquisa, através da análise de material elaborado pela Secretaria da Educação e o impacto deste nos sujeitos escolares.
\end{abstract}

Palavras-chave: gestão democrática, ensino público, política de Estado, participação

\section{PUBLIC EDUCATION DEMOCRATIC MANAGEMENT IN THE UPS AND DOWNS OF THE IDEOLOGICAL- POLITICAL EVENTS IN RIO GRANDE DO SUL}

\begin{abstract}
This article presents an extract of a research which tries to understand the changes in the education management in the state public education in Rio Grande do sul when a reform in public education, including modifications in the management process, is to be approved. The aim is to identify the meaning of this proposition to democracy in the public educational system, based on the questioning that has persisted for a long time over the role of democratic education management. This work is supported on the qualitative approach of the research, through analysis of documents from the State Education Secretary and its impact on the school workers and students.
\end{abstract}

Keywords: democratic management, public education; state policy, participation 
Falar sobre gestão educacional e as suas decorrências na gestão escolar em um momento marcado pela crescente complexidade das organizações, requer, não só a elucidação de alguns conceitos e entendimento de práticas que considero imprescindíveis a todos àqueles que participam do processo educacional, mas acima de tudo, direcionar o olhar ao processo sob o qual estamos envolvidos, às linguagens. Estamos submersos num processo de expropriação das linguagens acerca do que parece ter sentido óbvio. Cooptadas do ideário progressista, as linguagens sobre gestão democrática, autonomia, descentralização, participação e qualidade encontram-se aprisionadas dentro de um campo de significações determinado.

Para isto pretendo, neste artigo, mostrar o enfraquecimento da democracia em um momento em que o governo do Estado do Rio Grande do Sul encaminha uma reforma na educação pública que inclui mudanças no processo de gestão, em especial na instalação da meritocracia. Para tal, o questionamento que persiste a longo tempo, desde quando se acena para estas mudanças, diz respeito à tão famigerada democracia que sofre a radicalização das lideranças - governo e entidade classista - na gangorra dos atuais acontecimentos. Mas, afinal, sobre qual democracia estamos falando? Ambos lançam mão da democracia, embora de um lado e de outro inviabilizam uma reforma negociada, utilizando-se de obstáculos políticos e ideológico, deixando a sociedade estarrecida e impotente nesta luta de forças antagônicas. A partir dessa constatação, a gestão democrática passa a ser vista como envolta por intencionalidades políticas e pedagógicas que precisam ser rejeitadas ou validadas através de correções e acréscimos.

\section{Afinal, para onde vai à gestão democrática?}

Cabe inicialmente citar a questão básica legal assegurada pela conquista das forças civil-democráticas, marcada pelos movimentos e protestos de abertura política do Brasil nos anos 80 - Os princípios da educação na Constituição Federal e na LDB nº 9394/96 - que garante a gestão democrática do ensino público. Posteriormente, vimos assegurada na legislação dos sistemas do ensino, a Lei n ${ }^{\circ}$ 10.576/95 alterada pela Lei n ${ }^{0}$ 11.695/o1 de Gestão Democrática do Ensino Público no RS e, em decorrência, as leis aprovadas nos diferentes municípios e outros Estados da União.

Temos, portanto, assegurado um direito há treze anos - a gestão democrática - e a questão a ser perseguida continua sendo a mesma de quando aprovamos a lei, ou seja, o que fazemos com a tão desejada gestão democrática, 
provocadora historicamente de intensos debates, contestações e confrontos. Afinal, enquanto educadores, o que significa e qual é a nossa responsabilidade quando falamos em gestão educacional e/ou gestão escolar? A hipótese inicial é que as idéias acerca de gestão democrática do ensino no Brasil, a despeito da gravidade dos problemas relativos à democracia, não se impuseram ao esperado discurso que transitou na tradição.

Preliminarmente, a Lei de Gestão Democrática do Ensino Público no RS marca a sua história na educação pública do Estado do Rio Grande do Sul, pelo fato de ser pioneira no Brasil no que tange à abertura de um processo de democratização no campo das conquistas sociais educativas. E, nesse sentido, não se pode deixar de enaltecer os avanços incontestáveis e tampouco ignorar, sobretudo, a interferência de toda sorte de interesses que os textos legais sofrem, principalmente àqueles relativos aos comprometimentos econômicos.

$\mathrm{Na}$ esteira dos acontecimentos históricos, a qualidade da educação tornạ-se bandeira de luta no regime democrático - fenômeno que começa a ganhar visibilidade no final da década de 70 e atinge seu ápice durante a década de 8o. Nesse período se desenvolveram formas de movimentos sociais, organizações políticas, atividades de luta por direitos que apontam para horizontes de negação e superação das grandes desigualdades sociais. Começa a se configurar um espaço de lutas do magistério nos territórios tingidos pelas reestruturações neoliberais.

No período de 1979 a 1991 os professores gaúchos, através de sua organização sindical, passaram a promover debates, encontros, seminários na tentativa de formular propostas para uma política educacional democrática que garantisse: o acesso e permanência das crianças e jovens na escola; a participação da comunidade escolar e de setores sociais na gestão do sistema de ensino e um projeto pedagógico voltado para constituição da cidadania (fortalecimento da escola pública); a implantação de um quadro de pessoal por escola; a participação no Conselho Estadual de Educação; a formação dos conselhos escolares e a valorização profissional. Posteriormente, passou a integrar esta agenda a eleição de diretores de escolas, junto às demais prioridades.

Neste campo de lutas do movimento sindical permeado de interações e possibilidades de diálogo entre os universos antagônicos é aprovada a Lei de Gestão Democrática do Ensino Público. É interessante observar que o processo de regulamentação dessa Lei coincide com a possibilidade de efetivação de diferentes políticas sob o manto da gestão democrática. Se, por um lado, os novos modelos de gestão incorporaram conquistas dos movimentos organizados e a relutância dos trabalhadores às formas de organização capitalista e respec- 
tiva gestão, de outro lado, também o Banco Mundial, a partir dos anos 90, adquire expressividade no âmbito das políticas públicas em função do papel que desempenhou e continua desempenhando junto aos países mais pobres, atuando como estrategista de desenvolvimento do modelo neoliberal.

A questão que se coloca é a de que a discussão da democratização vem de longa data e afunilou o entendimento de que ela está alicerçada em três eixos basilares, que são: a universalização do ensino, a qualidade do ensino e a gestão democrática e participativa. Neste sentido, se a gestão democrática ocorre não só mediante a existência dos conselhos escolares, mas também está ligada diretamente à eleição de diretores e a autonomia da escola, garantia esta já conquistada, as perguntas que não cessam são as seguintes: por que hoje estamos sujeitos a perdas significativas de conquistas se temos em nossas mãos instrumentos legítimos de garantia de qualidade do ensino? Como se justifica a vulnerabilidade dos educadores frente a modelos que se impõem em nome do nosso fracasso enquanto educadores promotores da formação do indivíduo, seu preparo para a cidadania e a inserção no mundo do trabalho? Assistimos passivos a intromissão daquilo que historicamente entendemos ser da competência dos educadores, ou seja, apontar os caminhos para a educação, sendo elaborado por um grupo minoritário que legisla, planeja para os educadores executarem.

Frente a isto tudo, constata-se que, embora tenha se avolumado em nosso meio a retórica da qualidade e da democracia no âmbito escolar, os padrões de gestão têm contribuído muito pouco para a melhoria do ensino. A gestão democrática revestida de avanços apresenta-se como algo gratuito, pronto, ou seja, parecendo uma concessão sem a necessidade de inclusão no movimento do mundo em processo. As linguagens sobre gestão democrática, autonomia, descentralização, participação e qualidade encontram-se aprisionadas dentro de um campo de significações determinado. Os atuais índices dos indicadores de qualidade têm mostrado que a educação no Estado do RS apresenta um diagnóstico abaixo do esperado e, em nome desses diagnósticos, os órgãos governamentais acabam por gerar projetos normativos e prescritivos que se impõem pelo fato de que as escolas não têm respostas empíricas teoricamente embasadas para combatê-las objetivamente, caracterizando-se como novos fenômenos a serem investigados nas pesquisas educacionais.

A gestão democrática da educação é, pela sua natureza, autonomia, participação, liderança e trabalho coletivo voltado para um processo de decisão e deliberação pública. Ela expressa o anseio do crescimento do indivíduo como cidadão e do crescimento da sociedade enquanto sociedade democrática. E,

REGAE, Santa Maria, v. 1, n. 1, jan./jun. 2009 
para atendimento destas necessidades ela se firma nos seguintes aspectos: administrativo, financeiro e pedagógico. O exercício de uma gestão conduzida de forma partilhada vai repercutir com sucesso na educação e no ensino, de forma que a escola, por si só, vai prescrever os conhecimentos e conteúdos essenciais a serem desenvolvidos que atendam a sua real função.

Para tal, ao tomar a gestão democrática como fenômeno investigativo neste trabalho, novos elementos são trazidos para a análise e elejo o processo democrático desencadeado no RS como pano de fundo para entendimento da gestão na educação pública gaúcha. Dar primazia a este processo passa a ser um dos desafios para reexaminar as posições analíticas que se apresentam, constituindo-se em indispensável e significativo subsídio frente às proposições apresentadas, ou seja, contribui para a ressignificação do conceito de gestão e seu significado em matéria de torná-lo cada vez mais próximo dos objetivos emancipatórios.

\section{Ação governamental como engessamento da gestão}

Diante dos acontecimentos que acenam para as mudanças na gestão da educação, comprova-se a idéia de que "vivemos contemporaneamente uma espécie de era do descarte dos conceitos, da substituição por conceitos novos de significantes vulneráveis" (STEIN, 1996, p.106). Em relação a estas alterações, ouso dizer que muitas das construções de deliberações democráticas na educação estão sofrendo um espancamento desferido pelas novas imposições e, consequentemente, vão metamorfoseando os significados e anunciando o óbvio que constitui aquilo que o senso comum intitula como verdadeiro: a falta de qualidade na educação pública.

Parto da idéia debatida na academia de que a democracia sofre mutações históricas e o trato sobre a mesma depende da primazia que os diferentes grupos dão sobre ela. Levanta-se a hipótese de que há um desvirtuamento do seu conceito que a leva ao empobrecimento nas suas determinações. Esse desvirtuamento está nos governos que elaboram políticas de Estado impositivas ou está nas escolas que não conseguem solidificar na prática os fundamentos da democracia? Tais indagações nos remetem para a seguinte afirmativa. Todos se encontram, de uma forma ou de outra, implicados como sujeitos e, por isso, se exige muita cautela quando usamos a palavra democracia. $\mathrm{O}$ fato de as pessoas se dizerem democratas não significa que acreditem na democracia ou que usem adequadamente os instrumentos.

Mas se exaltamos tanto a democracia não seria coim vistas a atingir um 
nível de qualidade de educação que atenda aos interesses da sociedade como um todo? Quais as dificuldades de se construir políticas de gestão voltadas para a emancipação social? Parto inicialmente de uma lacuna visivelmente exposta que diz respeito à falta de projetos realmente voltados para a emancipação dos sujeitos. Ao desenvolver uma agenda de apresentações do Projeto Professor Nota 10 - valorização do magistério, como parte do Programa Estruturante Boa Escola para Todos, o Governo do Estado, através da Secretaria da Educação prevê como ações a formação continuada de professores e uma nova legislação para o sistema educacional do RS. Para atingir o objetivo de melhoria da educação elabora princípios para a nova carreira, coloca como prêmio a remuneração variável por desempenho das escolas (metas de aprovação e aprendizagem dos alunos) e a escolha dos dirigentes escolares mediante certificação, eleição com mudanças e contrato de gestão. Isso tudo como contra partida firmada pelo Governo do Estado no Acordo de Empréstimos junto ao BIRD.

Atônitos, a comunidade escolar assiste a imposição de projetos de reformas na educação do RS promovidas pelo governo do Estado. Frente a esta imposição cabe levantar a seguinte afirmação: a lei de gestão democrática do ensino é uma falácia. Pois o mesmo Estado que delega organização democrática para as instituições escolares, ao mesmo tempo faz valer a mesma estrutura hierarquizada e verticalizada de entender o público como objeto de privilegiamento de interesses dos especialistas da classe governamental. É uma nova forma de governar aos moldes dos governos autoritários. A diferença é a linearidade do tempo e o clima de turbulência que se presencia nas escolas, mas a tomada de decisão fica limitada aos espaços dos construtores de políticas de governo. Reafirma-se a função do Estado estritamente como de regulação, ou seja, de planejamento e execução de políticas educacionais sem a criação de espaços de deliberação democrática. Em detrimento a esta questão, o governo, enquanto gerenciador do Estado formula políticas públicas que traduzem seus propósitos em programas e ações que atendam muito mais os interesses de grupos e coalizões que integram o governo do que os interesses de outros segmentos que não o próprio governo. A obstrução de canais de comunicação entre estas diferentes instâncias de elaboração e execução de políticas faz com que os sistemas de acompanhamento e avaliação se transformem em letra morta. 


\title{
3 Uma luz no túnel: a participação
}

Para BARBOSA (1999) os novos conceitos de gestão se constituem numa preocupação da Administração Pública da Educação na busca de um novo paradigma. Acreditando na necessidade de se investir na gestão participativa, acrescenta que a Administração Pública deve ganhar maior espaço local, pois o aumento de poderes sugere a ampliação de responsabilidades e, conseqüentemente, maior preparo dos gestores educacionais.

\begin{abstract}
A gestão da escola passa a ser então o resultado do exercício de todos os componentes da comunidade escolar, sempre na busca do alcance das metas estabelecidas pelo projeto político-pedagógico construído coletivamente. A gestão democrática, assim entendida, exige uma mudança de mentalidade dos diferentes segmentos da comunidade escolar. A gestão democrática implica que a comunidade e os usuários da escola sejam os seus dirigentes e gestores e não apenas os seus fiscalizadores ou meros receptores de serviços educacionais (BARBOSA, 1999, p. 219).
\end{abstract}

Ao enfatizar a importância da construção do projeto político-pedagógico da escola, obviamente encontra-se aí presente a necessidade de que a gestão se opere pelas vias da participação. Assim, a gestão participativa envolve em suas atividades além do diretor, os professores e funcionários, os alunos, os pais e qualquer membro da comunidade externa da escola que esteja empenhado em colaborar com a melhoria do processo pedagógico. Para DOURADO (1998) a construção de um projeto político-pedagógico de uma escola é o ponto de partida para o estabelecimento de sua proposta, pois "a sua construção implica aprendizado do jogo democrático entre os vários interlocutores da escola (professores, conselho, funcionários, etc.). Trata-se de uma luta política e, portanto, deve envolver todos os segmentos na busca da ruptura com a cultura autoritária da escola" (Id. Ibid. p. 91). Neste sentido, cabe ressaltar que a sociedade brasileira convive com a ausência de uma verdadeira cultura de participação, conforme mostram diversos estudos (TORRES, 1995; TEIXEIRA, 2000, DOURADO, 1998).

A partir dos conceitos acima apresentados sobre gestão democrática, a atual prática de democracia desenvolvida pelas comunidades escolares tem mostrado que ainda estamos distantes de atender as necessidades básicas da educação, o que ratifica a idéia de que os instrumentos que a democracia dispõe estão distanciados do interesse da comunidade escolar, ou seja, desenvolver a autonomia do indivíduo.

Na prática cotidiana, tenho assistido verdadeiros impasses quanto aos 
espaços de responsabilidade de Governo e escolas na definição e implementação de políticas públicas, as quais geram desconfortos consideráveis, repercutindo diretamente nos processos de gestão escolar. Em decorrência, cada vez mais se questiona a prática democrática desenvolvida nas escolas e constata-se que a nossa vivência democrática é muito incipiente. Vivemos a predominância de uma tradição clientelista em nível local. O clientelismo, a falta de capacidade de pressão da população e a distribuição desigual dos bens públicos em nível local são algumas questões com as quais as formas de democracia não são capazes de lidar adequadamente.

Existe, no entanto, uma maneira de avaliar a democracia que requer que nos distanciemos da concepção hegemônica de democracia. São as práticas societárias. Nelas podemos substituir práticas das elites e o particularismo decorrente por formas ampliadas de discussão e tomada de decisão.

Sem querer fazer projeções, pois o processo social e político é muito dinâmico, insisto na superação desses desafios o que dependerá de um esforço conjugado e sustentado de participação dos cidadãos, valorizando o espírito público e a construção social. O termo gestão de origem latina significa chamar a si, executar, gerar. Neste sentido, o papel dos gestores como protagonistas da gestão é de genitor (que dá origem) e, para tal, se impõe como requisito inadiável a luta pela conquista de espaços de autonomia e socialização do poder. Isso faz com que a escola provoque a desobstrução de canais de participação com os sistemas de ensino e, ao mesmo tempo, crie uma força motriz capaz de impulsionar os educandos para o sucesso sem a interferência de intromissões alheias ao processo educacional.

Na perspectiva de Boaventura de Sousa Santos (2002), a democracia apresenta potencialidades, mas também apresenta vulnerabilidades e ambigüidades que precisam ser socializadas. É certo também afirmar que a nossa democracia é de baixa intensidade, o que não impede de caminharmos em busca de seu aprimoramento como meio de assegurar uma educação para a pessoa humana e não para á formação de recursos humanos. Através do aprimoramento de práticas de democratização é possível visualizar novos horizontes de emancipação, fundada na autonomia e que podem ocorrer em contextos específicos, através da valorização do espaço local.

O que se defende aqui são proposições construídas coletivamente, tendo como balizador o conhecimento fundado em justificativas éticas para dar suporte na tomada de decisões políticas. Nesse sentido, passa a ser imprescindível a valorização de novas formas de organizações de deliberação democrática que possam se sustentar e constituir-se em dispositivos de criação de novas 
teias sociais na construção de políticas públicas de educação.

Se fosse possível representá-los graficamente, poderíamos vê-los como algo semelhante a uma rede neuronal ou a uma teia, no interior da qual todas as partes estão ligadas e interconectadas, e onde cada "ponto" está ligado ao outro. Algo como sistemas não hierarquizados, em que cada parte constituinte alimenta e é alimentada pela outra. (MORAES, 2004, p.233)

A desconstrução piramidal de relações de poder através da socialização horizontalizada é um dos caminhos para um processo de democratização. Os sistemas interligados proporcionam uma conexão direta em que o diálogo poderá se reverter em possibilidades de construções eticamente elaboradas onde todos poderão ter vez e voz para construir a vontade coletiva. Para isso, a valorização de espaço-tempo local passa a ser uma alternativa possível na aproximação de tão grandes diferenças.

\section{A valorização do local como alternativa para o processo de democratização da gestão}

A educação configura-se pela sua abrangência como um dos campos sociais mais importantes de multiplicidade e diversidade das mais diferentes experiências, desde o planejamento de políticas públicas no âmbito da gestão educacional até o espaço escolar, caracterizado pelas suas peculiaridades locais. Conjugada com a idéia de que todos estão de uma forma ou de outra envolvidos no estabelecimento de objetivos, tomada de decisões, proposições de planos de ação, implementação, acompanhamento e avaliação, a participação só será efetivada mediante um processo previamente organizado e que tenha um verdadeiro sentido político-democrático.

Para isso, pressupõem-se inicialmente interesses comuns a todos os envolvidos neste processo. Deste modo, democratizar a educação significa, entre outras práticas, uma disposição para o diálogo. A partir desta perspectiva, a gestão democrática passa a ser vista como o meio de desenvolver relações mais democráticas entre os atores educativos envolvidos num processo coletivo de conhecimentos e construção do saber. Os gestores e o conselho escolar podem permitir o estabelecimento de ligações e a possibilidade de aflorar novos conhecimentos. Para isso o principal objetivo é o encorajamento de uma dinâmica e estabelecimento de mecanismos sustentados de gestão conjunta. Cada um na escola tem que reconhecer o seu papel, suas atribuições e responsabilidades no processo e ter a clareza de que a ação é coletiva. O desenvolvimento da auto- 
nomia na escola dependerá do potencial de organização de base comunitária que são os professores, os alunos, os pais, a comunidade em geral onde a escola está situada. Este terreno é acidentado. Através desse olhar e assumir consciente, quando é possível perceber as deformações a que foram submetidos os processos educacionais e as organizações, é que o diálogo buscará estabelecer consensos que orientarão a prática educativa. Esse processo é marcado pela diversidade e confronto de argumentos com vistas à mudança política, social e cultural em direção à novas aprendizagens e ao estabelecimento de normas que orientarão o processo pedagógico, validado por todos os envolvidos.

No entanto, corre-se o risco de enfrentamento de idéias desestabilizadoras. E aí eu parafraseio Boaventura de Sousa Santos (2002) quando diz que a rotina da mobilização atrai uma mobilização da rotina e, para isso, há necessidade de uma permanente vigilância sistêmica e epistemológica.

Desta forma, o objetivo da gestão democrática é de desobstruir os canais da comunicação distorcida, para que os sujeitos possam se relacionar de forma livre, embora reconhecendo as pressões sistêmicas. A ativação dos canais de comunicação permite que a escola produza o contato e o encontro possível de saberes não considerados, produzidos no âmbito local e que estão aprisionados no mundo sistêmico e não são reconhecidos como saberes. O diálogo entre diferentes posições faz com que haja transparência de demandas, enriquecendo um e outro, de tal maneira que os atores estabelecem, assim, a fusão de mundos compartilhados. Desta forma, a comunidade escolar, sob e com a mediação dos gestores, passa a ter clareza dos seus propósitos e finalidades, priorizando os objetivos que atendam às expectativas da comunidade escolar e promovam, assim, o sucesso de seu alunado.

É substancial a tomada de consciência de que algo precisa ser feito, caso contrário, a gestão democrática parece estar em toda parte e em parte nenhuma, sob várias formas e sem objetivos claros suscetível, sujeita a todas as formas de intromissões alheias ao processo educativo. A aplicação dos normativos legais que propõem a autonomia das escolas, eleição de diretores e participação em órgãos colegiados tem vindo a acentuar normas e poderes funcionais. Com efeito, cabe ressaltar os elementos simbólicos que participam na condução das práticas, ou seja, os atos de vontade, as crenças e as idéias pedagógicas. A não inclusão desses elementos faz com que o ideário pretendido não se sustente e possa ser reduzido à dependência, à conformidade e à subordinação a interesses adversos. A autonomia instrumental pode ser gerida conforme as circunstâncias, ora contraindo, ora expandindo o seu âmbito na gangorra de delegações políticas. 
A ausência de uma cultura de participação é que favorece a omissão dos sujeitos e a tendência em delegar obrigações para os dirigentes, ao mesmo tempo em que desenvolve e consolida uma cultura organizacional, no sentido de que todos são conduzidos a explorar um espaço intraorganizacional e assim permanecer nele. Por si só a eleiçã̃o de diretores e também a de membros do conselho escolar não rompe com a hierarquização da autoridade na escola, ao mesmo tempo em que não apresenta alterações profundas no processo democrático.

Portanto, antever possibilidades de reinvenção da emancipação social no campo da gestão democrática do ensino, a partir das experiências desenvolvidas em escolas públicas, situadas em contextos urbanos e rurais que priorizem a democratização dos diferentes saberes, passa ser o desafio para os desejosos de democracia. Neste sentido, embora as forças contrárias tentem impor a sua vontade, a comunidade escolar inserida em um processo social participativamente atuante, tem força para reverter as imposições à seu benefício. A sociedade gaúcha vive um momento nevrálgico na história da educação. A gestão da educação pública realmente se encontra na gangorra dos acontecimentos políticos no RS, o que não impede uma ação conjunta como forma de alavancar realmente os seus interesses. É a construção de um processo educacional que poderá desmantelar uma dependência histórica de mandos na educação. Por isso a insistência na organização local como espaço para a construção de políticas públicas que atendam verdadeiramente as necessidades locais, respeitar a diversidade local, étnica, social e local.. As políticas elaboradas por especialistas, prática comum na nossa sociedade, só vem ressaltar o Estado regulador que se revela a cada nova perspectiva de reformas.

Para mudar esse quadro, há que se lançar perspectivas possibilitadoras de processos emancipatórios, através da organização das comunidades e, ao mesmo tempo, as escolas devem assumir cada vez mais uma crítica séria para os estudos que envolvem a democracia e a gestão do ensino, constituindo-se em objetivo a ser perseguido por aqueles engajados nesta caminhada, o que requer um contínuo processo de reflexão frente às verdades que se impõem.

\section{Referências}

BARBOSA, Jane Rangel Alves. Adminstração pública e a escola cidadã. Revista Brasileira de Política e Administração da Educação . Porto Alegre, v. 15, n. 2, p. 217-226, jul/dez, 1999.

DOURADO, Luiz Fernandes. A escolha dos dirigentes escolares: políticas de 
gestão da educação no Brasil. In: FERREIRA, Naura Syria C. Gestão democrática da educação: atuais tendências, novos desafios. São Paulo: Cortez, 1998.

MORAES, Salete Campos de. É possível a construção de políticas públicas emancipatórias em educação? Revista Portuguesa de Educação, CIED Universidade do Minho, Portugal. 2004.

SANTOS, Boaventura de Sousa (org.). Democratizar a democracia: os caminhos da democracia participativa. Rio de Janeiro: Civilização Brasileira, 2002.

STEIN, Ernildo. Aproximações sobre hermenêutica. Porto Alegre: EDIPUCRS, 1996.

TEIXEIRA, Lucia Helena G. Cultura organizacional da escola: uma perspectiva de análise e conhecimento da unidade escolar. Revista Brasileira de Política e Administração da Educação - ANPAE. Porto Alegre, v. 16, n. 1, p.7-22, jan/jun. 2000.

TORRES, Leonor Maria Lima. Cultura organizacional escolar: um estudo exploratório a partir das representações dos professores. Dissertação de mestrado. Instituto de Educação e Psicologia da Universidade do Minho. Braga. Portugal, 1995.

\section{Maria Elizabete Londero Mousquer}

Doutora em Educação pela UFRGS

Professora do Departamento de Administração Escolar do Centro de Educação da UFSM

E-mail para correspondência:

betemousquer@yahoo.com.br 